\title{
Synthesis and Modeling of Temperature Distribution For Nanoparticles Produced Using Nd:YAG Lasers
}

\author{
Mu'ataz S. Hassan, ${ }^{1}$ Ziad A. Taha, ${ }^{1}$ and Bassam G. Rasheed ${ }^{2}$ \\ ${ }^{1}$ Institute of Laser for Postgraduate Studies, University of Baghdad, Baghdad, Iraq \\ ${ }^{2}$ Laser and Optoelectronics Engineering Department, Al Nahrain University, Baghdad, Iraq \\ Correspondence should be addressed to Bassam G. Rasheed; dr_bassamghalib@yahoo.com
}

Received 19 June 2016; Revised 5 August 2016; Accepted 24 August 2016

Academic Editor: Oded Millo

Copyright (C) 2016 Mu'ataz S. Hassan et al. This is an open access article distributed under the Creative Commons Attribution License, which permits unrestricted use, distribution, and reproduction in any medium, provided the original work is properly cited.

\begin{abstract}
Nanosecond pulses of Nd:YAG laser were employed to produce silver and silicon nanoparticles by laser ablation process in liquid. Two Nd:YAG laser systems of 6 and 10 nanoseconds pulse duration with variable laser energy in the range $700-760 \mathrm{~mJ}$ were employed. Morphological investigation using AFM and TEM reveals the formation of silver and silicon nanoparticles with uniform size distribution. It is found that mean nanoparticles sizes of 50 and $70 \mathrm{~nm}$ for silver and silicon, respectively, are produced under similar laser parameters. Moreover, theoretical model was used to estimate the temperature distributions for both silver and silicon nanoparticles. It is also found that the maximum temperature of about $50 \mathrm{k} \mathrm{K}^{\circ}$ and $70 \mathrm{k} \mathrm{K}^{\circ}$ for silver and silicon nanoparticles, respectively, is generated when Nd:YAG of $10 \mathrm{~ns}$ is used to prepare nanoparticles. Zeta potential measurements reveal that silver nanoparticles are more stable than those of silicon prepared by similar conditions.
\end{abstract}

\section{Introduction}

The Nanoscience defines a set of technologies and developments that are based on physical, chemical, and biological phenomena occurring at the nanoscale ranging from approximately 1 to 100 nanometers [1]. In general, there are two approaches to fabricate nanomaterials: bottom-up and topdown [2]. Nanomaterials can be classified as zero-, one-, two-, and three-dimensional nanostructures $[3,4]$.

Synthesization methods of nanomaterials can be conducted by chemical methods or physical methods. The physical methods are exploding wire technique, physical vapor deposition, thermal evaporation, sputtering deposition, chemical vapor deposition, and laser ablation, while the formation of NPs using laser ablation consists of two types: dry and wet laser ablation. For different target materials and varying parameters such as the laser wavelength, fluency, and pulse duration, it is possible to produce a wide variety of compounds nanoparticles. Moreover, Pulse Laser Ablation in Liquid (PLAL) involves the interaction between the laser and target which can also be used to synthesize colloidal suspension of nanoparticles [5]. PLAL is a one-step top-down procedure (dispersion method) strategy of nanoparticles preparation [6]. The main advantages of this technique are its ability to produce various kinds of nanomaterials such as metals, noble metals, semiconductors, nanoalloys, oxides, and magnetic and core-shell nanostructure [7], with no need for vacuum equipment [8], and the surfactant molecules can control on aggregation $[9,10]$.

Pulse lasers have very interesting applications in various fields such as industrial and medical and in measurements like range finders. Moreover, pulsed lasers are also used in ablation but it is limited in nanotechnology since microparticle sizes are often produced. Aim of this work is to study effects of some laser parameters on production of smaller nanoparticles and the temperature distribution of ejected particles.

\section{Methodology}

In this research, two Nd:YAG laser systems were used for the ablation process. Nd:YAG laser providing pulses of $1064 \mathrm{~nm}$ with maximum energy per pulse reach $1000 \mathrm{~mJ}$, pulse duration of $10 \mathrm{~ns}$, and a maximum repetition rate equal 
to $6 \mathrm{~Hz}$, while the second has $850 \mathrm{~mJ}$ energy and $6 \mathrm{~ns}$ pulse duration and $10 \mathrm{~Hz}$ maximum repetition rate. The Nd- YAG laser beam was focused using a lens of $10 \mathrm{~cm}$ focal length onto silver and silicon target.

Silver metal ounces plates of high purity listed of 99.999 were used. The plates were polished and then cleaned in ultrasonic bath by a cleaner (soda, sodium bicarbonate, and hot water). Then, they are washed with ethanol and distilled water before cutting into small pieces to suite the experimental arrangement. Commercial silicon wafer of 0.5$3 \Omega \cdot \mathrm{cm}$ resistivity (100) orientation and $500 \mu \mathrm{m}$ thickness was employed in this work. This wafer has polished face which is subjected to the laser radiation. Before preparation, samples were rinsed in acetone and ethanol to terminate any impurities, eventually; they also immersed in electronic grade aqueous $20 \% \mathrm{HF}$ acid to complete the cleaning process.

Double distilled and deionized water DDDW is necessary to prepare the nanoparticles colloidal solutions in this work.

Morphological investigation using optical microscope, atomic force microscope (AFM), and transmission electron microscope (TEM) were conducted to study the geometry, size, and size distribution of the prepared nanoparticles. Zeta potential experiments were also carried out to explore the aggregation of the nanoparticles in the colloidal suspension.

Mathematical calculations were carried out using MathCad 14 software package. The experimental data concerning the size and their distribution for silver and silicon nanoparticles were used in the point source solution of the heat flow theory to estimate the temperature distribution for various nanoparticles sizes that could be obtained

\section{Results and Discussion}

3.1. Mathematical Model Results. Depending on the basis of understanding laser-material interaction, a mathematical model simply predicts future conditions and used the equation:

$$
\begin{aligned}
T(t) & =\frac{2 \cdot F O}{k}\left[(\alpha \cdot t)^{1 / 2} \frac{e^{-\left[z /\left(2 \cdot(\alpha \cdot t)^{1 / 2}\right)\right]}}{\pi^{1 / 2}}\right. \\
& -\frac{z}{2 \cdot(\alpha \cdot t)^{1 / 2}}[1-1 \\
& \left.\left.-\left(a \cdot b+A 1 \cdot b^{2}+C \cdot b^{3}\right) e^{-\left[z /\left(2 \cdot(\alpha \cdot t)^{1 / 2}\right)\right]^{2}}\right]\right],
\end{aligned}
$$

where $T(t)$ is temperature (K), Fo is surface absorbed power $\mathrm{W} / \mathrm{m}^{2}, k$ is thermal conductivity $\mathrm{W} / \mathrm{m} \cdot \mathrm{K}, \alpha$ is thermal diffusivity $\mathrm{m}^{2} \mathrm{~s}^{-1}, t$ is time, $z$ is depth, $t$ is time power off, and $a$, $A 1, C$, and $b$ are constants [11].

The temperature distribution of silver and silicon nanoparticles was estimated using the convolution of the size distribution with the heat flow theory as follows:

$$
\begin{aligned}
T\left(r_{1}\right) & =\int_{r}^{r_{o}} N \cdot D(R) \\
& \frac{(2 \cdot P(1-r f)) /\left(6 \cdot 10^{3} \cdot v\left(r_{1}\right)\right)}{k}\left[(\alpha \cdot t)^{1 / 2}\right.
\end{aligned}
$$

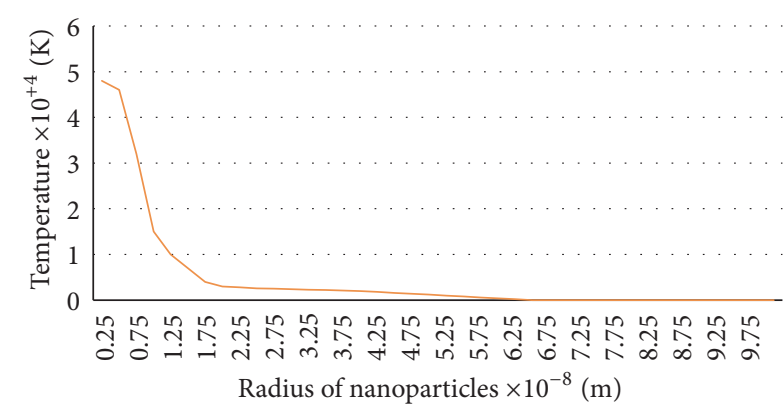

Figure 1: The relation between the temperature and radius for nanoparticles of the laser has the pulse duration $10 \mathrm{~ns}$ for $740 \mathrm{~mJ}$ for silver nanoparticles.

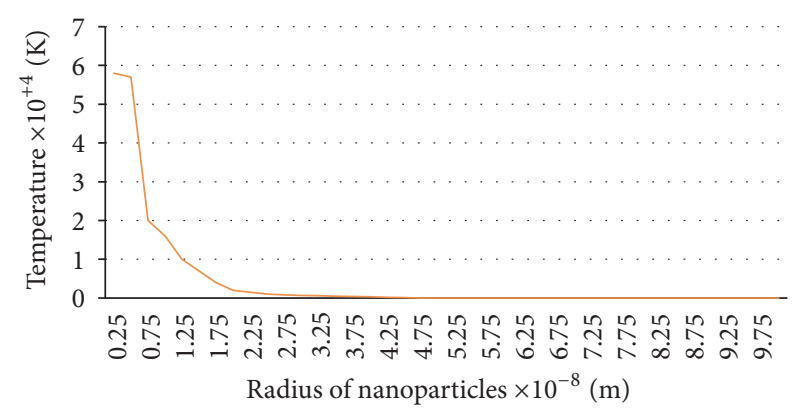

FIGURE 2: The temperature and radius for silver nanoparticles prepared by laser of pulse duration $6 \mathrm{~ns}$ and $740 \mathrm{~mJ}$ energy.

TABLE 1: Comparison between the Ag NPs produced by $1064 \mathrm{~nm}$ has 6 and 10 ns pulse duration.

\begin{tabular}{lcc}
\hline Laser pulse duration & $\begin{array}{c}\text { Molten depth } \\
(\mu \mathrm{m})\end{array}$ & $\begin{array}{c}\text { Maximum } \\
\text { temperature }\left(\mathrm{K}^{\circ}\right)\end{array}$ \\
\hline $6 \mathrm{~ns}$ & 7 & $50 \mathrm{k}$ \\
$10 \mathrm{~ns}$ & 9 & $40 \mathrm{k}$ \\
\hline
\end{tabular}

$$
\begin{aligned}
& \cdot \frac{e^{-\left[z /\left(2 \cdot(\alpha \cdot t)^{1 / 2}\right)\right]}}{\pi^{1 / 2}}-\frac{z}{2 \cdot(\alpha \cdot t)^{1 / 2}}[1-1 \\
& \left.\left.-\left(a \cdot b+A 1 \cdot b^{2}+C \cdot b^{3}\right) e^{-\left[z /\left(2 \cdot(\alpha \cdot)^{1 / 2}\right)\right]^{2}}\right]\right] d r .
\end{aligned}
$$

The solutions of (1) and (2) are represented in Figures 1, 2 , and 3; Figures 1 and 2 show the relation between the temperature and radius for nanoparticles for silver nanoparticles while Figure 3 shows between the size distribution of $S i$ and generated temperature.

A comparison between the theoretical results that have been obtained for both lasers of $10 \mathrm{~ns}$ and the $6 \mathrm{~ns}$ are given in Table 1.

Table 1 indicates that the temperature increases to $10 \mathrm{k} \mathrm{K}^{\circ}$ when the laser pulse duration decreased from $10 \mathrm{~ns}$ to $6 \mathrm{~ns}$. Similarly, calculations were conducted for silicon as given in Figure 3 and Table 2. 


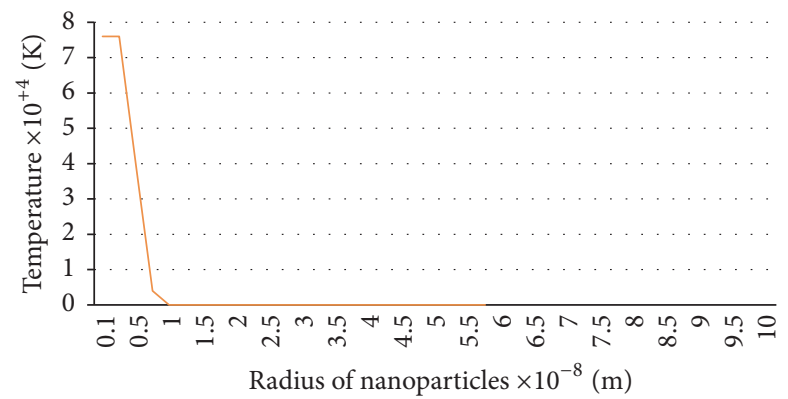

Figure 3: The relation between the temperature and radius for silicon nanoparticles prepared by laser of $10 \mathrm{~ns}$ for $740 \mathrm{~mJ}$.

TABLE 2: Comparison between the Ag and Si NPs produced by $1064 \mathrm{~nm}$ has $10 \mathrm{~ns}$ pulse duration.

\begin{tabular}{lc}
\hline Nanoparticles & Maximum temperature $\mathrm{K}^{\circ}$ \\
\hline Silver & $50 \mathrm{k}$ \\
Silicon & $70 \mathrm{k}$ \\
\hline
\end{tabular}

By comparison between the $\mathrm{Ag}$ and $\mathrm{Si}$, it is found that the temperature of the silicon nanoparticles is higher about $20 \mathrm{k} \mathrm{K}^{\circ}$ from silver.

Table 2 also indicates that, under identical laser conditions, higher temperature distribution is created in silicon compared with that in silver and this implies production of a large number of nanoparticles in silicon.

3.2. Experimental Results. TEM images of silver (Ag) nanoparticles, produced using laser ablation with pulse duration of $6 \mathrm{~ns}$ and energy of 700 and $720 \mathrm{~mJ}$, are represented in Figures 4(a) and 4(b), respectively. It is found that silver nanoparticles sizes increased with increasing the laser energy due to high aggregation of small nanoparticles produced by higher energy. Formation of small nanoparticles is attributed to the decreasing in the generated temperature and vapor pressure which lead to ejecting small silver nanoparticles. One should also mention a secondary effect due to laser interaction with nanoparticles during the ablation process. But since the preparation time (interaction time) takes few minutes (less than 10 minutes), this effect is not effective compared with the aggregation time (many days after preparation). Therefore, the large surface area effect of smaller nanoparticles takes place and enhances the aggregation effect and increases the net size. To overcome this problem one should use ultrasonic frequency of about $1 \mathrm{GHz}$ to separate nanoparticles in the colloidal suspension.

Figures 5(a) and 5(b) show a TEM image of silver and silicon nanoparticles, respectively, prepared by laser energy of $700 \mathrm{~mJ}$, with wavelength of $1064 \mathrm{~nm}$ and pulse duration of $10 \mathrm{~ns}$. It is clearly observed that the diameter of $\mathrm{Si}$ nanoparticles of $20 \mathrm{~nm}$ is smaller than that of $\mathrm{Ag}$ of $50 \mathrm{~nm}$. This is attributed to high absorption coefficient of Si to the Nd:YAG laser wavelength which leads to the laser radiation making the generated temperature much lower [12].

One can compare between $\mathrm{Ag}$ and Si using histogram Figures 6(a) and 6(b) observed. It is that the size of nanoparticles for $\mathrm{Si}$ has better distribution (homogeneous distribution) compared with $\mathrm{Ag}$ because of high $\mathrm{Si}$ absorption coefficient of laser $(1064 \mathrm{~nm})$. This also generates temperature and vapor pressure, which subsequently leads to ejecting small silicon nanoparticles.

Nanostructured surfaces morphology was also examined using AFM. Figures 7(a), 7(b), 7(c), and 7(d) show the 3D AFM images of Ag nanoparticles at various energies of 700, 720,740 , and $760 \mathrm{~mJ}$, respectively. It is clearly observed that the Ag nanoparticles become uniform and smooth with increasing the energy to $720 \mathrm{~mJ}$ with average surface roughness of $1.05 \mathrm{~nm}$; however, by increasing the energy to 740 and $760 \mathrm{~mJ}$ the surface can be rough more than before with average surface roughness of 1.52 and $7.18 \mathrm{~nm}$, respectively. The surface roughness attributed to the increment of the laser energy and vapor pressure because the generated temperature leads to ejecting smaller silver nanoparticles.

From Figures 8(a), 8(b), 8(c), and 8(d) we observed that the diameter of silver NPs is increasing with increasing the energy, due to the high aggregation of small nanoparticles produced by higher energy, because the energy, temperature, and vapor pressure are increasing for production of the $\mathrm{Ag}$ NPs. In Figure 8(b), the observation is the best distribution (homogeneous distribution) at $740 \mathrm{~mJ}$ rather than 700,720 , and $760 \mathrm{~mJ}$ because the $\mathrm{Ag}$ at the energy $740 \mathrm{~mJ}$ absorbed the laser $(1064 \mathrm{~nm})$ better than at the energy of 700, 720, and $760 \mathrm{~mJ}$.

Similarly, three-dimensional AFM images of silicon nanoparticles showed that, in Figure 9, the surface roughness of Si nanoparticles increased with the increasing of laser energy from 700, 720, 740, and $760 \mathrm{~mJ}$ and the average surface roughness is $1.08,2.37,1.73$, and $2.39 \mathrm{~nm}$, respectively. The increment in the surface roughness is attributed to the increased laser energy and size of Si nanoparticles.

In Figure 10(b), best nanoparticles size distribution is found (homogeneous distribution) at low laser energy of $700 \mathrm{~mJ}$ rather than 720,740 , and $760 \mathrm{~mJ}$ because the silicon wafer highly absorbs the Nd:YAG laser photon energy $(1.1 \mathrm{eV})$ due to the resonance with silicon band gap energy $(1.1 \mathrm{eV})$ [13] and higher energy $740 \mathrm{~mJ}$ produces smaller sizes but with great aggregation which in turn increases the overall size distribution.

Figures 11(a), 11(b), 12(a), and 12(b) show the UV-Vis absorption spectra of Ag and Si nanoparticles, respectively. All spectra were measured for nanoparticles prepared by 700 and $760 \mathrm{~mJ} /$ pulse with Nd:YAG laser of $1064 \mathrm{~nm}$ wavelength.

The peaks of UV-Vis spectra for silver nanoparticles prepared with $700 \mathrm{~mJ}$ observed at $429 \mathrm{~nm}$ indicate that the mean size was $50 \mathrm{~nm}$, while for silicon nanoparticles $645 \mathrm{~nm}$ implies that the mean nanoparticles size was $70 \mathrm{~nm}$. This peak shifts to $414 \mathrm{~nm}$ when silver particles are prepared by $760 \mathrm{~mJ}$ laser energy. This could be attributed to the effect of formation of smaller nanoparticles due to the high generated temperature.

The presence of single surface plasmon peak implied that the formed nanoparticles are nearly spherical while in the case of ellipsoidal particles the absorption spectrum would have two plasmon peaks [14]. 


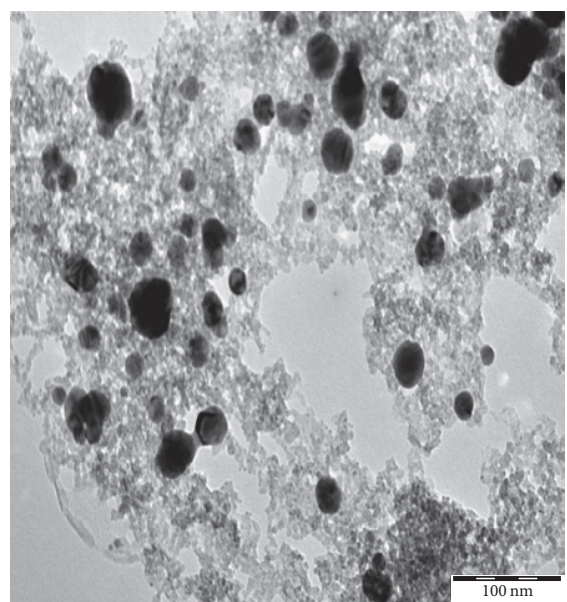

(a)

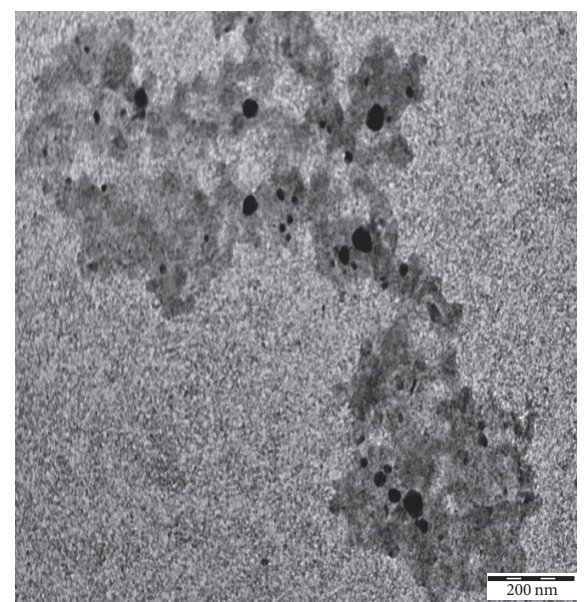

(b)

FIgURE 4: TEM images of silver nanoparticles at energy of (a) $700 \mathrm{~mJ}$ for $6 \mathrm{~ns}$ pulse duration and (b) $720 \mathrm{~mJ}$ for $6 \mathrm{~ns}$ pulse duration.

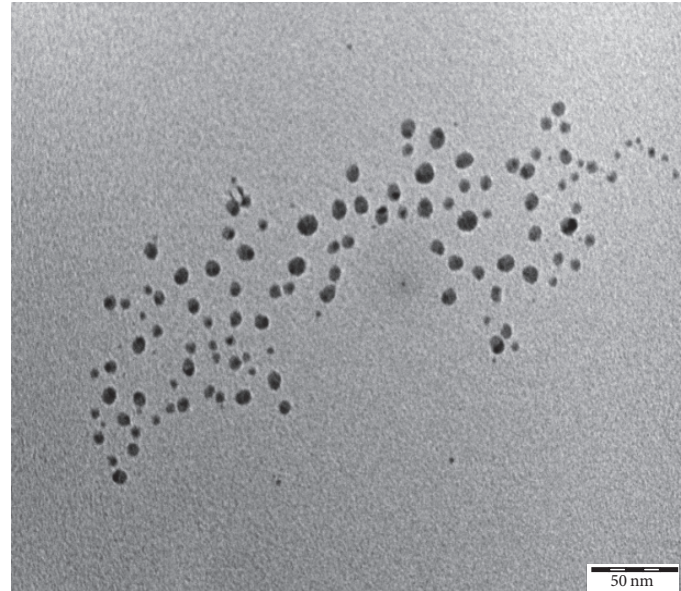

(a)

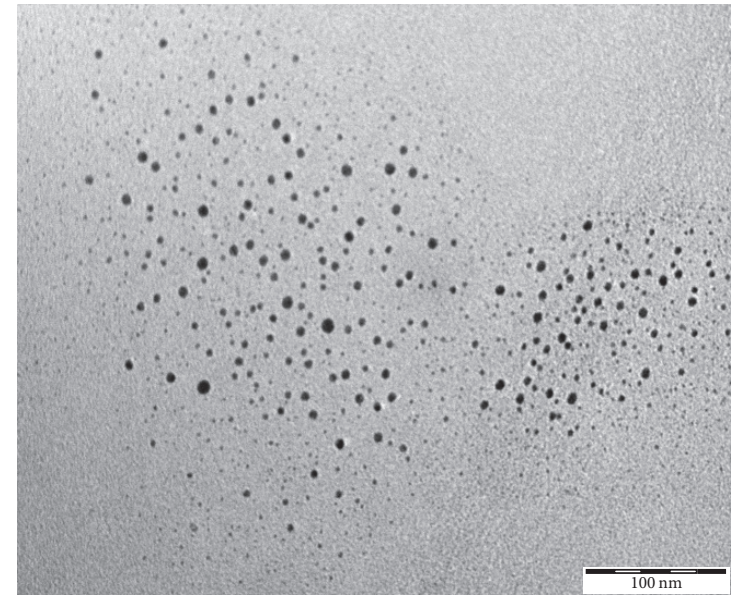

(b)

FIGURE 5: TEM images of (a) silver nanoparticles at energy of $700 \mathrm{~mJ}$ for $10 \mathrm{~ns}$ pulse duration and (b) silicon nanoparticles at energy of $700 \mathrm{~mJ}$ for $10 \mathrm{~ns}$ pulse duration.

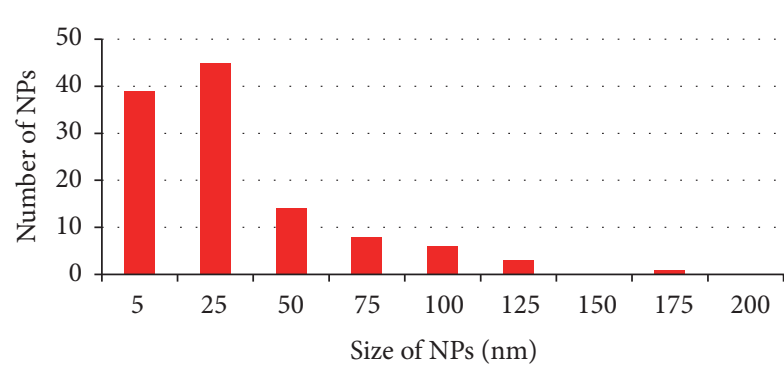

(a)

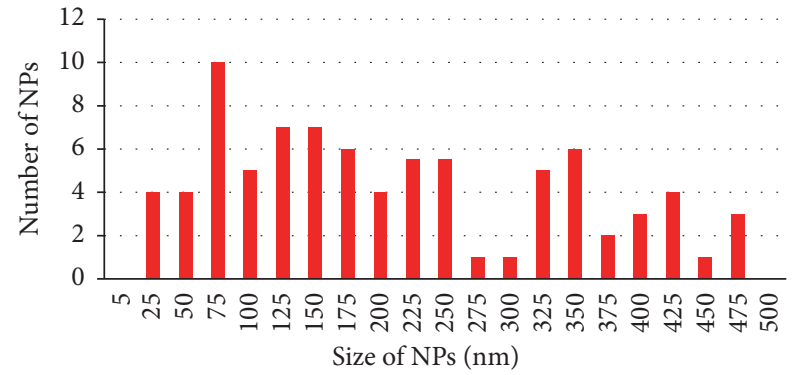

(b)

FIGURE 6: TEM histogram for (a) silver nanoparticles prepared by energy of $700 \mathrm{~mJ}$ and $10 \mathrm{~ns}$ pulse duration and (b) silicon nanoparticles prepared by energy of $700 \mathrm{~mJ}$ and $10 \mathrm{~ns}$ pulse duration. 


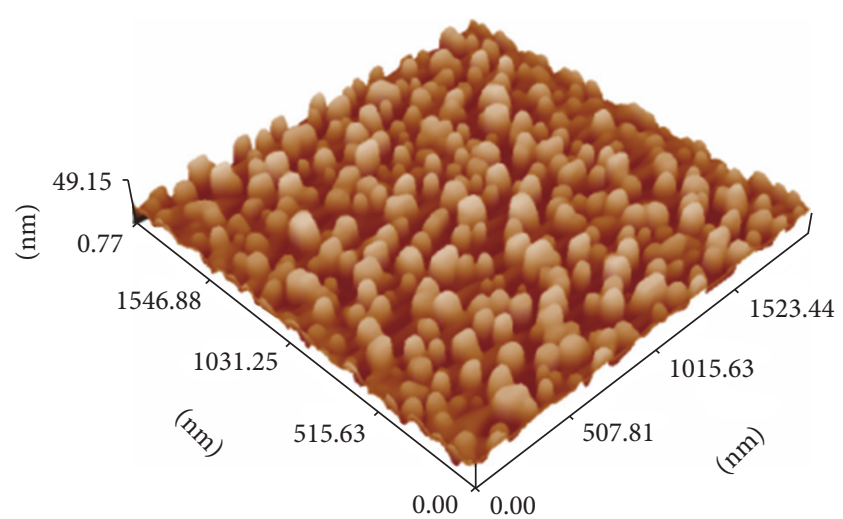

(a)

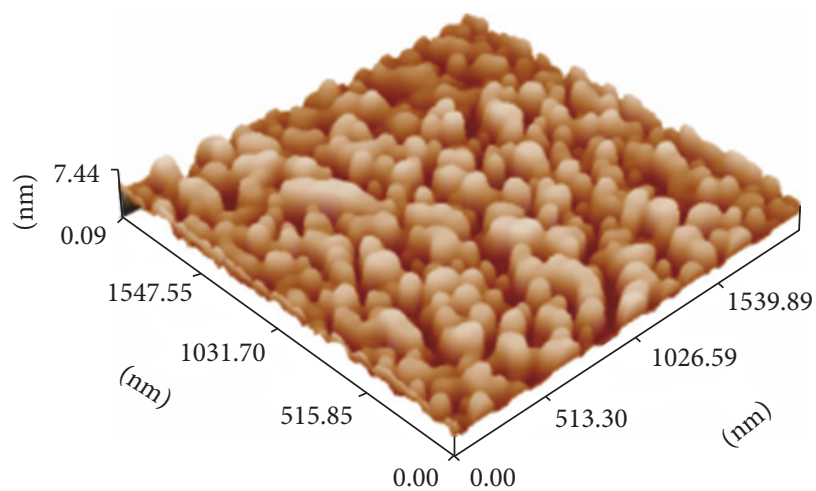

(c)

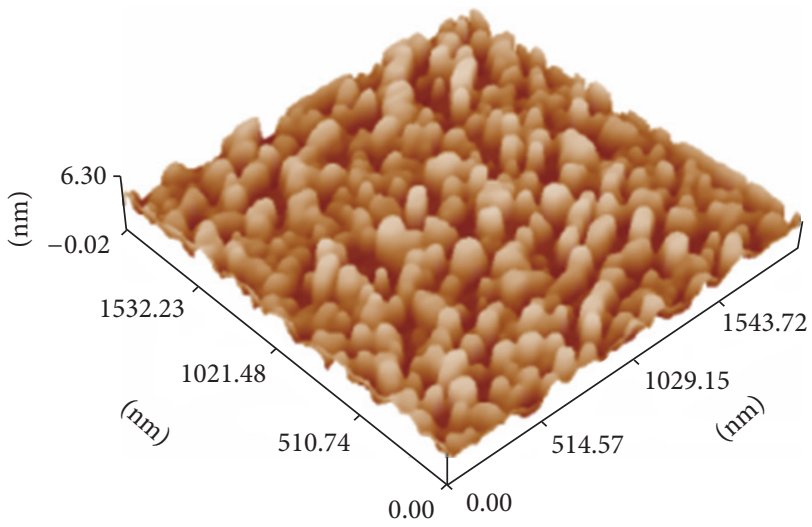

(b)

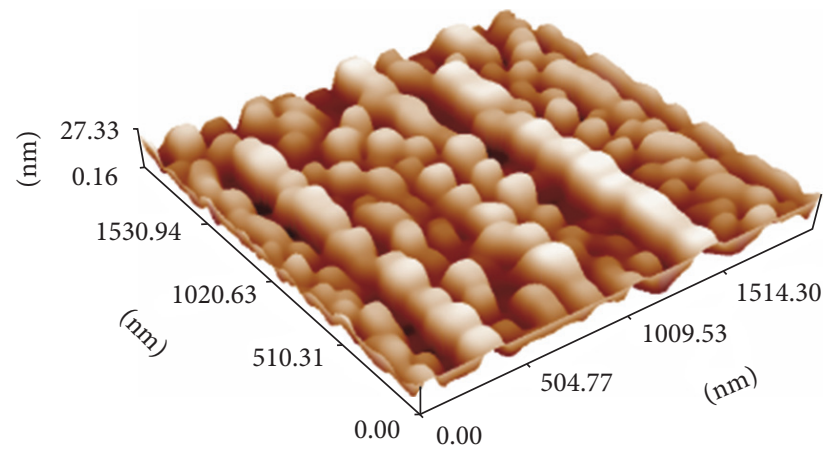

(d)

Figure 7: AFM images for Ag for (a) $700 \mathrm{~mJ}$, (b) $720 \mathrm{~mJ}$, (c) $740 \mathrm{~mJ}$, and (d) $760 \mathrm{~mJ}$.

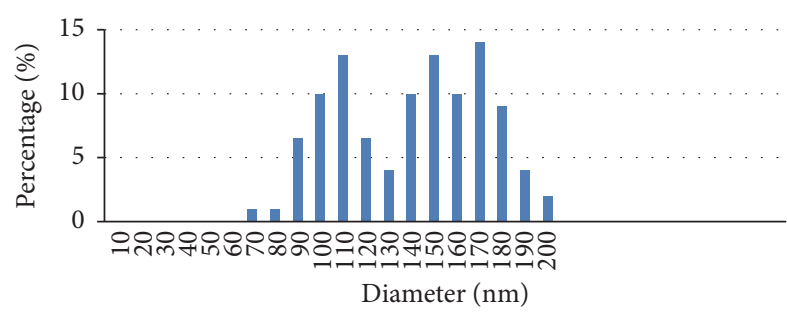

(a)

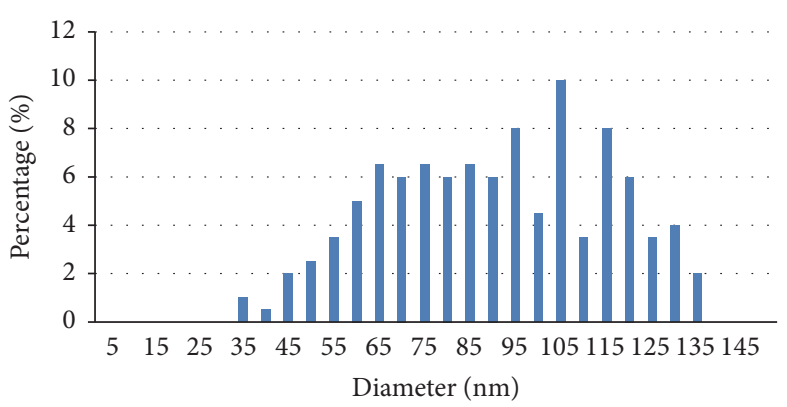

(c)

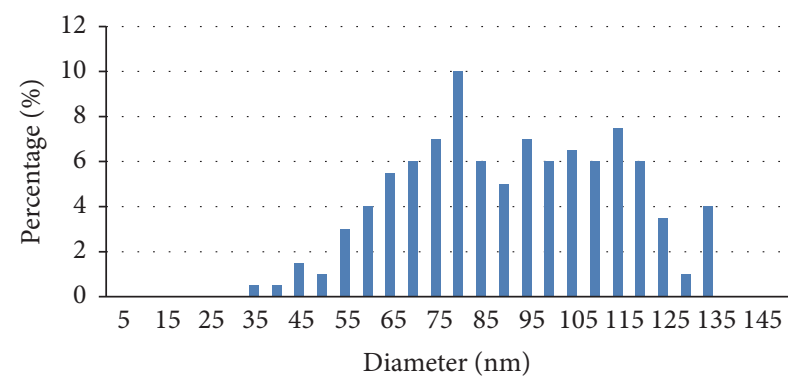

(b)

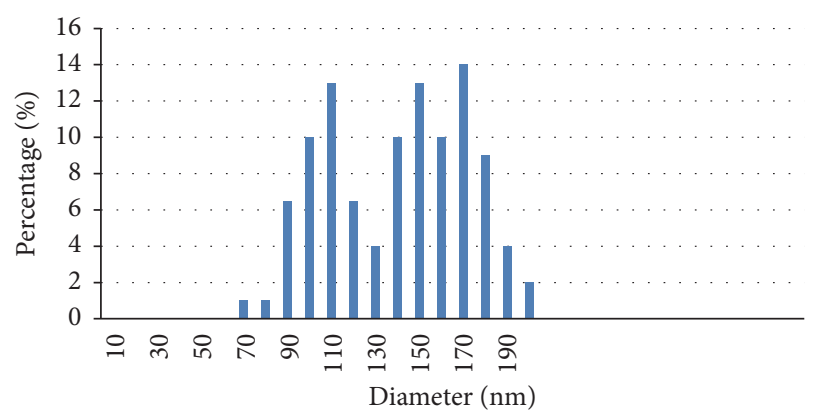

(d)

FIgURE 8: Size distribution for Ag at (a) $700 \mathrm{~mJ}$, (b) $720 \mathrm{~mJ}$, (c) $740 \mathrm{~mJ}$, and (d) $760 \mathrm{~mJ}$. 


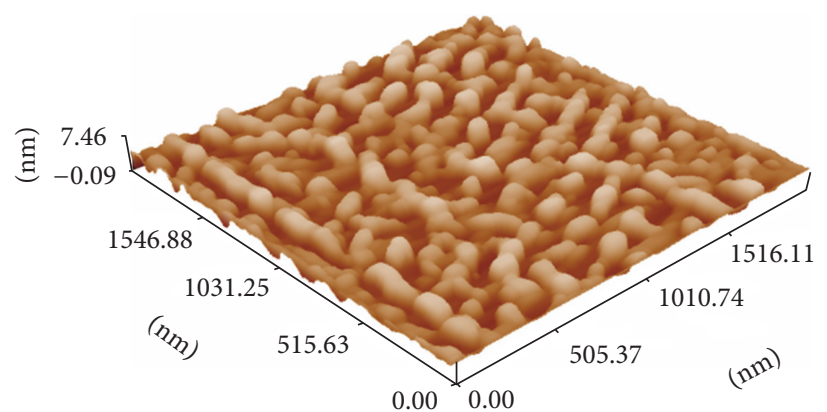

(a)

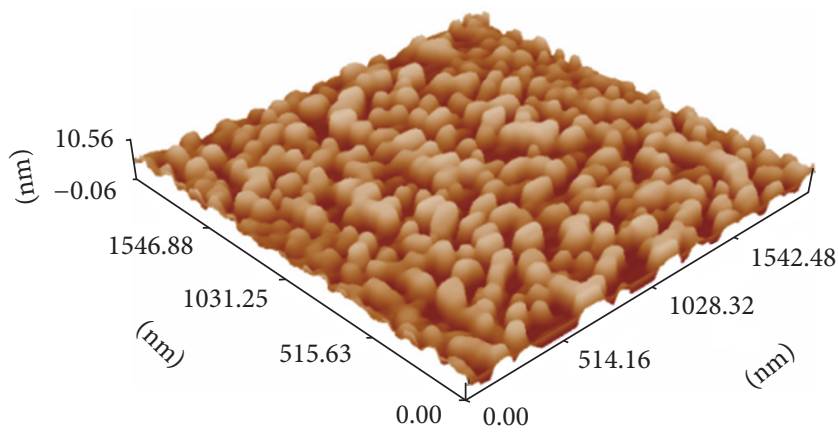

(c)

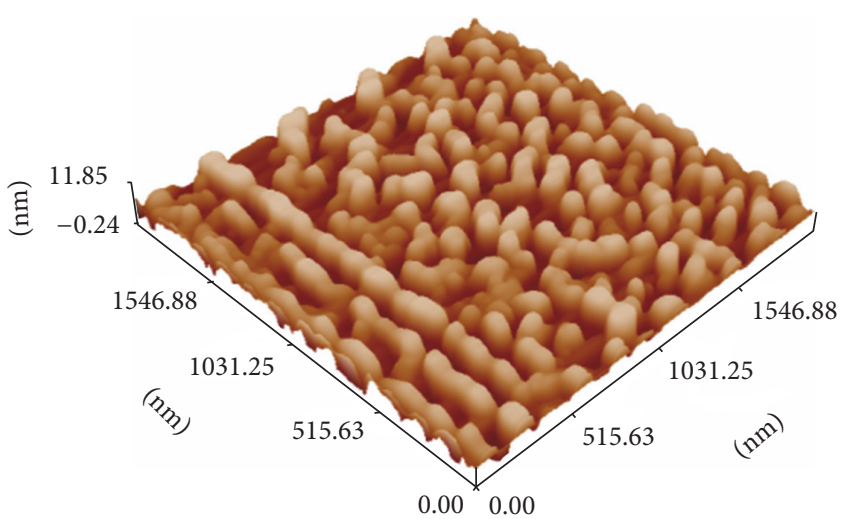

(b)

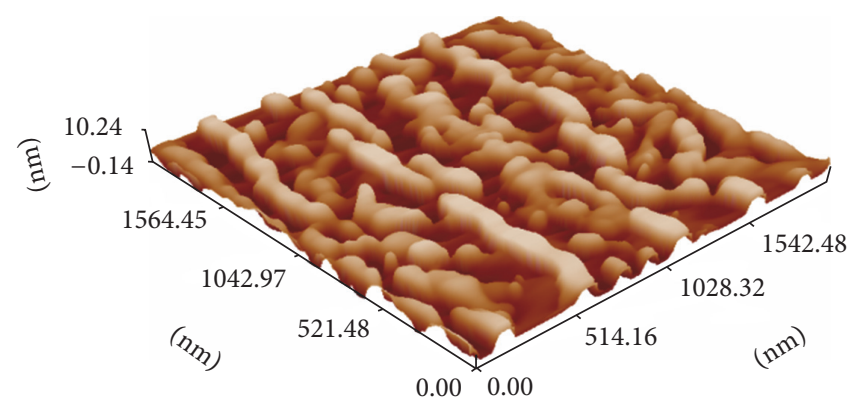

(d)

Figure 9: AFM images for Si of (a) $700 \mathrm{~mJ}$, (b) $720 \mathrm{~mJ}$, (c) $740 \mathrm{~mJ}$, and (d) $760 \mathrm{~mJ}$.

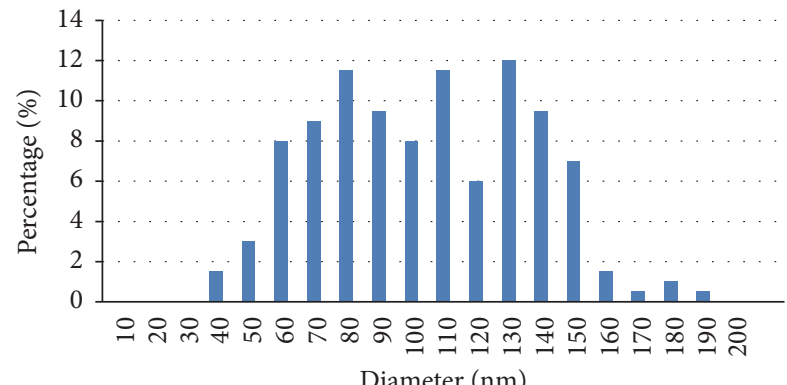

(a)

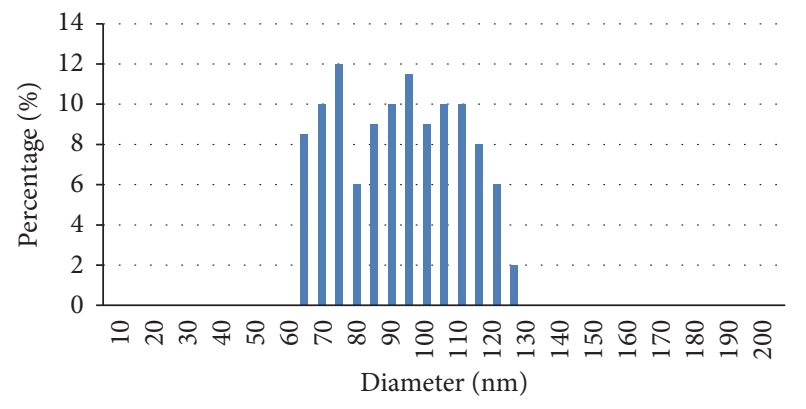

(c)

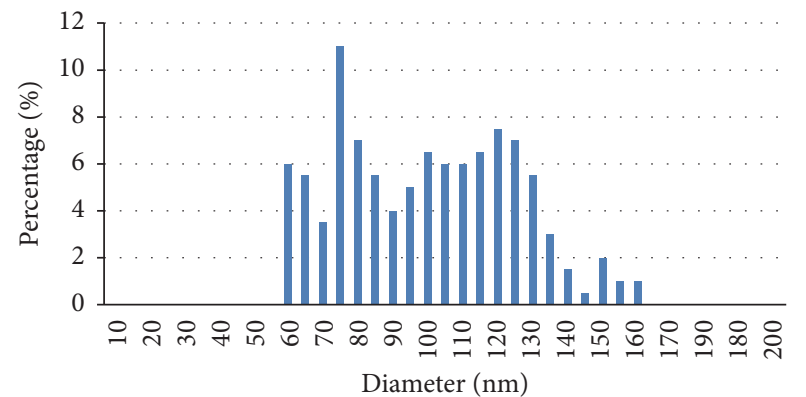

(b)

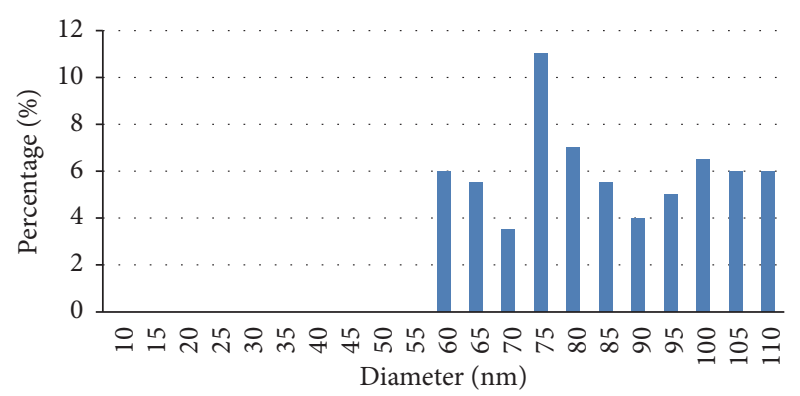

(d)

FIGURE 10: The size distribution for silicon nanoparticles prepared by (a) $700 \mathrm{~mJ}$, (b) $720 \mathrm{~mJ}$, (c) $740 \mathrm{~mJ}$, and (d) $760 \mathrm{~mJ}$. 


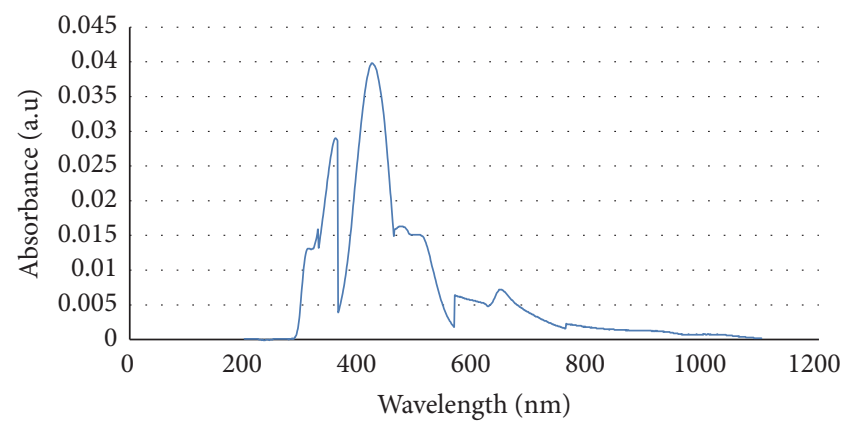

(a)

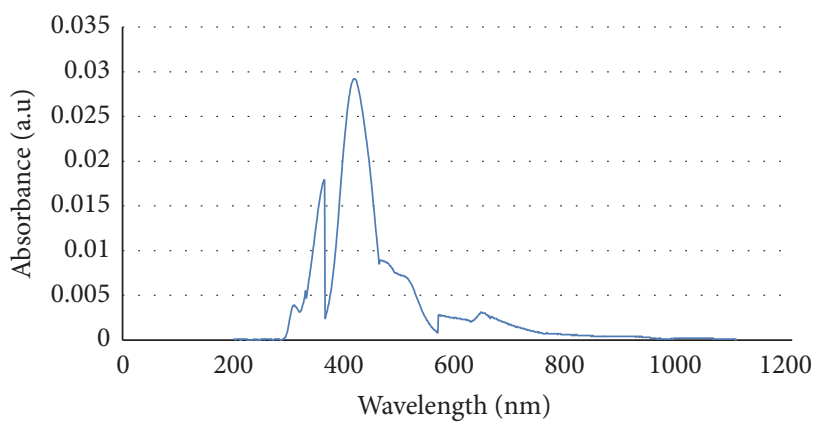

(b)

FIGURE 11: UV-VIS absorption spectra of silver nanoparticles solution prepared by 200 pulses with laser energy of (a) $700 \mathrm{~mJ}$ and (b) $760 \mathrm{~mJ}$.

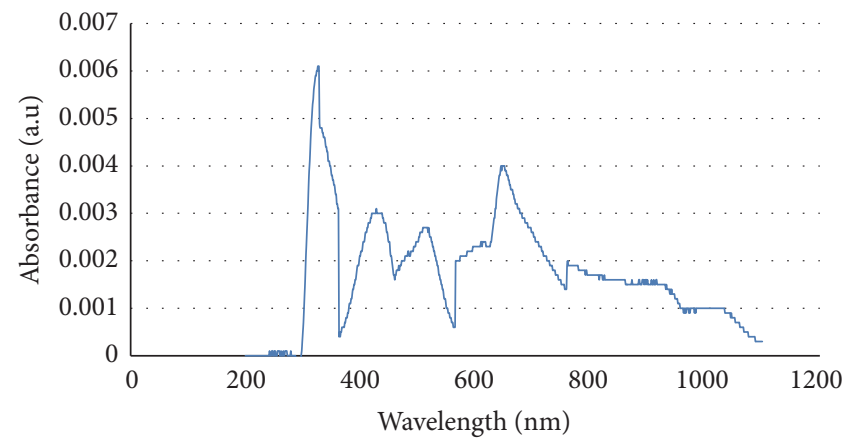

(a)

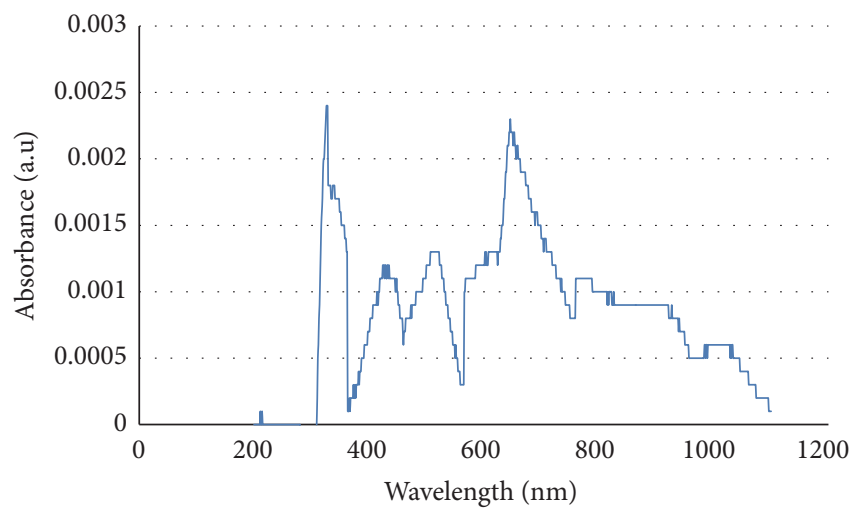

(b)

FIGURE 12: UV-VIS absorption spectra of silicon nanoparticles solution prepared by 200 pulses and energy of (a) $700 \mathrm{~mJ}$ and (b) $760 \mathrm{~mJ}$.

The stability of produced nanoparticles via their values was normally considered stable between above $+30 \mathrm{mV}$ and less $-30 \mathrm{mV}$ and that agrees with criteria values in Z-potential inspection. In silver the mean value of $Z$-potential was $-49.42 \mathrm{mV}$ and the mean value of the silicon was low $-23 \mathrm{mV}$ shown. That means silver nanoparticles are more stable than silicon nanoparticles.

\section{Conclusions}

Silver and silicon nanoparticles could be prepared by laser ablation in liquid. It is found that silver nanoparticles are more stable than those of silicon. Temperature distribution of higher magnitude was observed for silicon nanoparticles compared with that for silver. The magnitude of maximum temperature increases when shorter laser pulses are used. Incorporating the experimental data for size distribution in the theoretical model provides a better understanding of the temperature distribution of nanoparticles produced by laser ablation. Homogeneous size distribution for silicon nanoparticles was achieved by low laser energy while better size distribution of silver nanoparticles can be obtained by higher laser energy.

\section{Competing Interests}

The authors declare that they have no competing interests.

\section{Acknowledgments}

This work was supported by the Institute of Laser for Postgraduate Studies, University of Baghdad.

\section{References}

[1] A. Kadhim, R. Gaayied, and M. Falah Noori, "Preparation of gold nanoparticles by pulsed laser ablation in $\mathrm{NaOH}$ solution," Journal of Babylon University: Pure and Applied Sciences, vol. 22, no. 1, pp. 547-551, 2012.

[2] P. V. Kazakevich, A. V. Simakin, and G. A. Shafeev, "Formation of periodic structures by laser ablation of metals in liquids," Applied Surface Science, vol. 252, no. 13, pp. 4457-4461, 2006.

[3] R. Psaro, M. Guidotti, M. Sgobba, and B. Sketches, Nanosystems, vol. 2, 2009.

[4] F. Kurniawan, New analytical applications of gold nanoparticles [Ph.D. thesis], University of Rogensburg, Regensburg, Germany, 2008.

[5] T. Tsuji, D.-H. Thang, Y. Okazaki, M. Nakanishi, Y. Tsuboi, and M. Tsuji, "Preparation of silver nanoparticles by laser ablation in polyvinylpyrrolidone solutions," Applied Surface Science, vol. 254, no. 16, pp. 5224-5230, 2008.

[6] A. Ali and D. Raouf, "Preparation of silver nanoparticles by pulsed laser ablation in liquid medium," Journal of Engineering \& Technology, vol. 29, no. 15, pp. 3058-3066, 2011. 
[7] R. Nakajima, X. Zhu, and T. Ishigaki, "Generation of Alumina nanoparticles by a nanosecond laser-induced liquid plasma in water," in Proceedings of the 20th International Symposium on Plasma Chemistry (ISPC '11), pp. 2-5, Philadelphia, Pa, USA, July 2011.

[8] J. S. Golightly, J. S. Golightly, and N. Winograd, Formation and Characterization of Nanoparticles via Laser Ablation in Solution, no. 1, 2007.

[9] D. Werner, S. Hashimoto, T. Tomita, S. Matsuo, and Y. Makita, "In-situ spectroscopic measurements of laser ablation-induced splitting and agglomeration of metal nanoparticles in solution," The Journal of Physical Chemistry C, vol. 112, no. 43, pp. 1680116808, 2008.

[10] I. Römer, T. White, M. Baalousha, K. Chipman, M. R. Viant, and J. R. Lead, "Aggregation and dispersion of silver nanoparticles in exposure media for aquatic toxicity tests," Journal of Chromatography $A$, vol. 1218, no. 27, pp. 4226-4233, 2011.

[11] W. Steen, J. Mazumder, and K. G. Watkins, Laser Material Processing, Springer, 4th edition, 2012.

[12] H. S. Mavi, B. G. Rasheed, A. K. Shukla, S. C. Abbi, and K. P. Jain, "Photoluminescence study of Nd:YAG laser-etched silicon," Journal of Non-Crystalline Solids, vol. 286, no. 3, pp. 162-168, 2001.

[13] B. G. Rasheed, H. S. Mavi, and A. K. Shukla, "Surface reconstruction of Nd:YAG laser etching of silicon," Material Science \& Engineering, vol. 79, article 70, 2001.

[14] A. T. M. Saeb, A. S. Alshammari, H. Al-Brahim, and K. A. Al-Rubeaan, "Production of silver nanoparticles with strong and stable antimicrobial activity against highly pathogenic and multidrug resistant bacteria," Scientific World Journal, vol. 2014, Article ID 704708, 9 pages, 2014. 

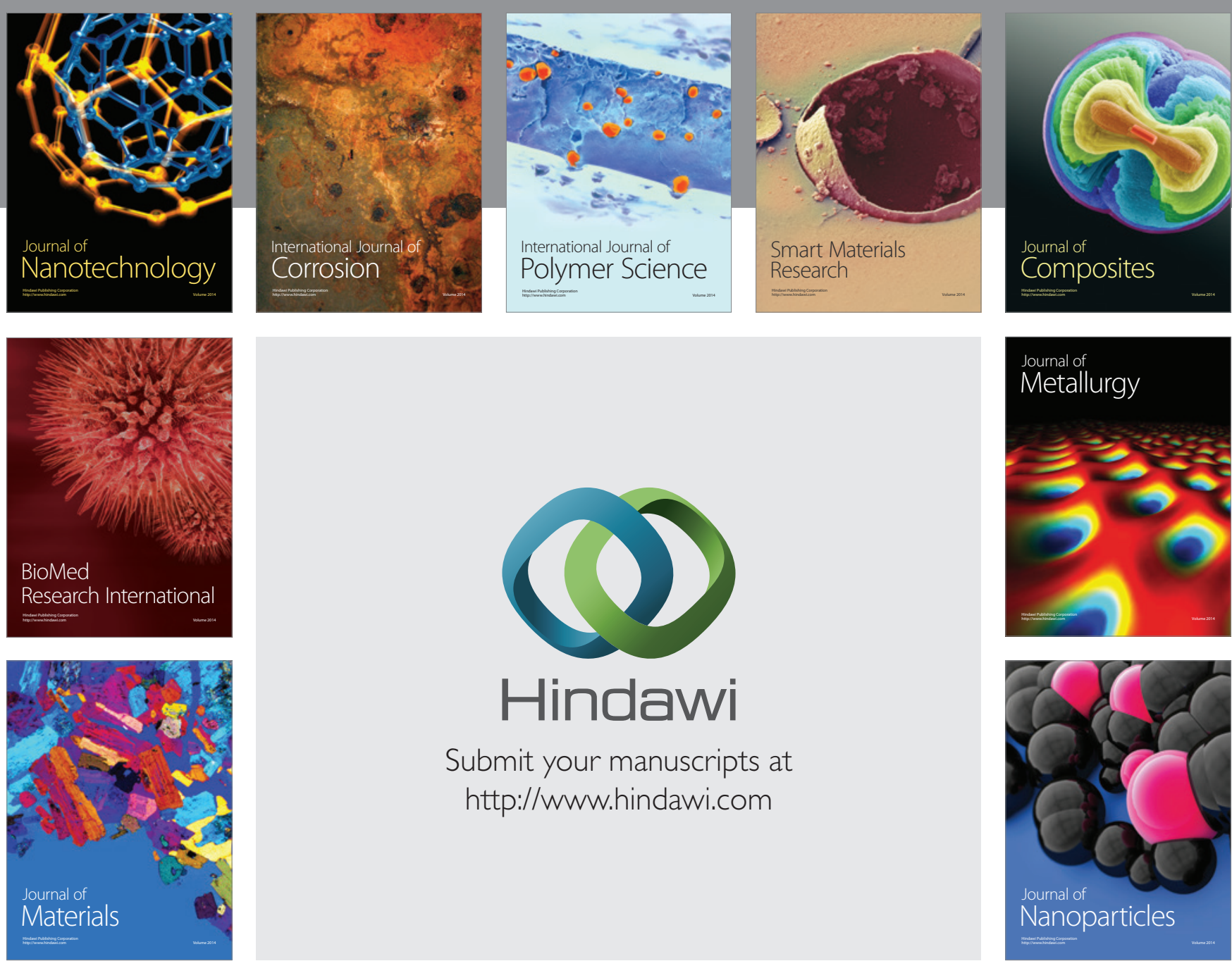

\section{Hindawi}

Submit your manuscripts at

http://www.hindawi.com

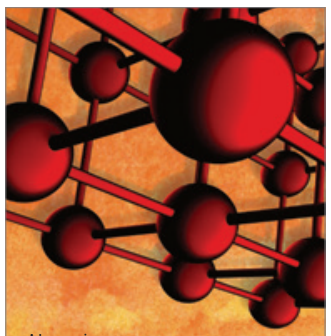

Materials Science and Engineering
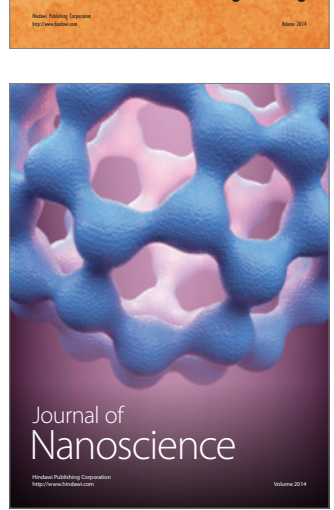
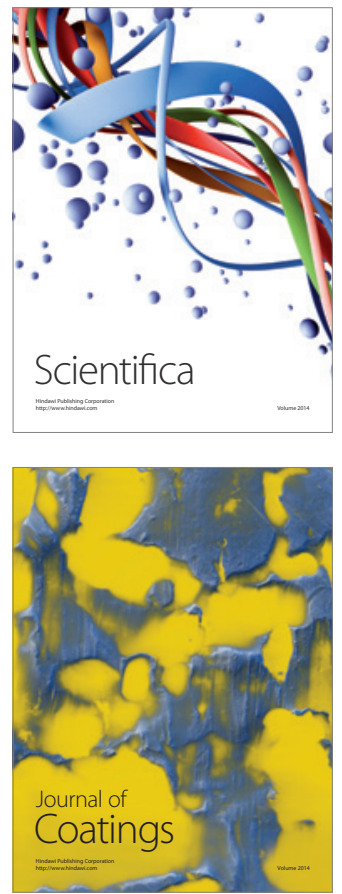
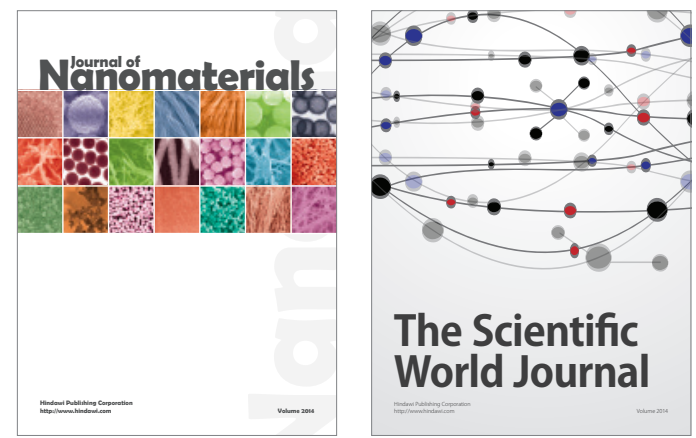

The Scientific World Journal
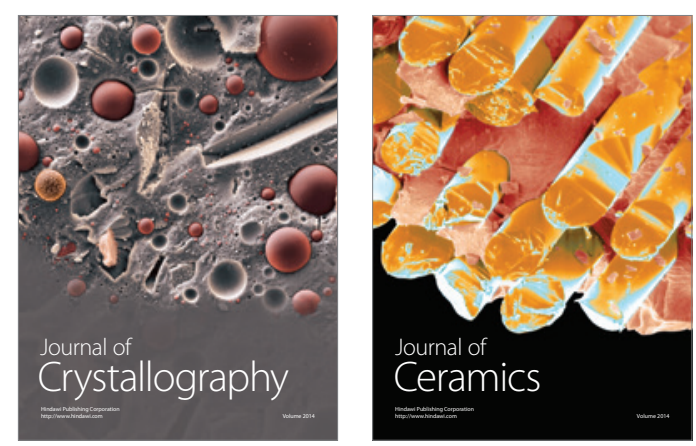
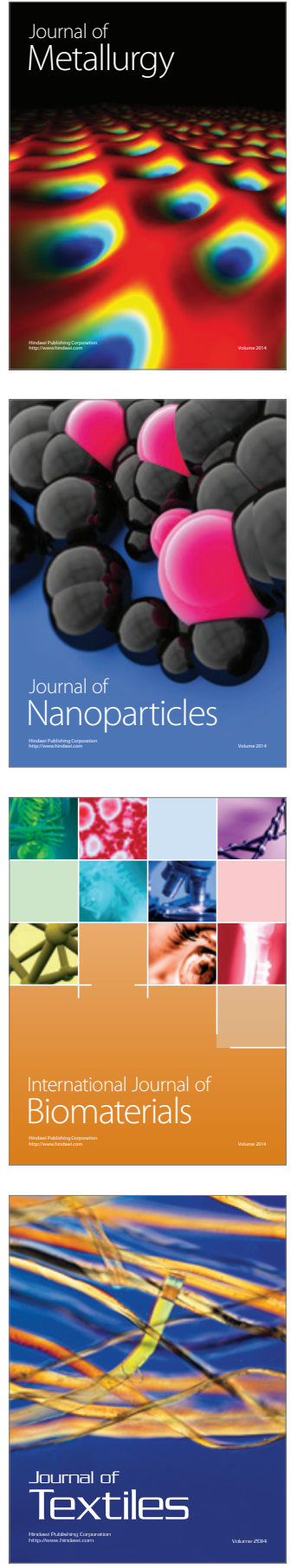